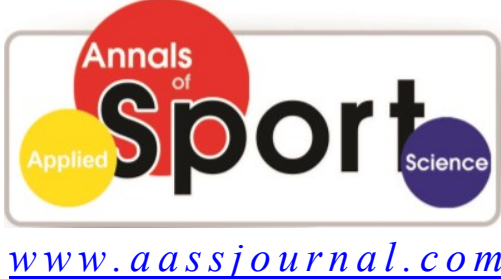

ISS N (Online): $2322-4479$

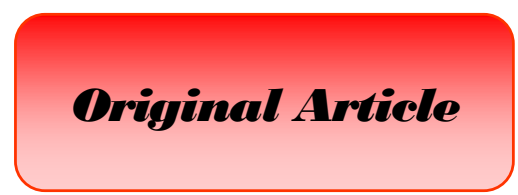

Received: $12 / 05 / 2014$

Accepted: 23/10/2014

\title{
The Effect of Shoe Outsole Containing Nanoclay Particles on Knee Joint Power during the Stance Phase of Running
}

\section{${ }^{1}$ Zahra Bassiri*, ${ }^{1}$ Mansour Eslami, ${ }^{2}$ Mousa Ghaemy, ${ }^{1}$ Seyed Esmaeil Hoseninejad, ${ }^{1}$ Mohammad Rebiei}

1. Department of Sport Biomechanics, Faculty of Physical Education and Sport Sciences, University of Mazandaran, Babolsar, Iran.

2. Department of Polymer Chemistry and Technology, Faculty of Chemistry, University of Mazandaran, Babolsar, Iran.

\begin{abstract}
The popularity of running and consequently of running injuries has increased tends to develop shoe sole constructions aiming at preventing different injuries. The purpose of this study was to investigate the effect of shoe outsole containing nanoclay particles on knee joint power during stance phase of running. Fourteen healthy male shod runners run 3 times at $3.5 \mathrm{~m} . \mathrm{s}-1$ under three shoe conditions manufactured by polyurethane (PU), 1\% Polyurethanes-clay nano-composites (NPU1) and 2\% Polyurethanes-clay nano-composites (NPU2). The joint power (Pj) was calculated by multiplying the joint moment $(\mathrm{Mj})$ and the joint angular velocity $(\omega \mathrm{j})$. Knee joint peak power in the three dimensional planes were compared between the shod conditions during the stance phase of running using repeated measurement ANOVA $(\mathrm{P}<0.05)$. The results showed that the negative peak of knee joint power in sagittal plane was significantly different between the PU and NPU2 conditions. No significant differences were noted in other positive and negative peaks. It is concluded that using Polyurethanesclay nano-composites can change shock absorbing ability of knee joint.
\end{abstract}

Key Words: Shoe Outsole, Nanoclay Particles, Knee Joint Power, Running.

Corresponding Author:

Zahra Bassiri

E-mail: zahrabassiri@gmail.com 


\section{INTRODUCTION}

The popularity of running is raising dramatically, because it is an efficient way to achieve fitness and promote long-term exercise $(1,2)$. In the wake of increasing number of recreational runners and, consequently, running injuries in the last decades, there has been increasing trends to study the effects of shoe sole constructions on the development of running injuries (3). Since it has been reported, wearing a well-designed footwear can alter the relevant running parameters to prevent running injuries (4).

For over forty years, biomechanics researchers and athletic footwear companies developed technical concepts in order to prevent different injuries (5). For example, Stacoff et al. (2000) tested shoe sole modification with alternation in sole geometry on tibiocalcaneal rotations (3). Furthermore, Stefanyshyn and Nigg (2000) inserted Carbon fiber plates into shoe midsoles and investigate its effects on energy generation and absorption of knee (6). But both of these studies reported no significant result.

Shoe outsole material is an effective factor that can alter the kinematics and kinetics of movements (7). Nowadays, several materials like Carbon rubber, Styrene-butadiene rubber (SBR), Microcellular rubber, Ethyl vinyl acetate (EVA), Polyurethane (PU), Polyvinyl chloride (PVC) and Hytrel are used in running shoe soles (8). Among them, Ethyl vinyl acetate (EVA) and Polyurethane (PU), get more attention.

Polyurethanes (PUs) are unique polymer materials with a wide range of physical and chemical properties that used in shoes outsole production $(9,10)$. PUs can be appropriate to meet manifold demands of various applications such as coatings, adhesives, fibers, thermoplastic elastomers, and foams. However, PUs have some disadvantages, such as low thermal stability, mechanical strength, resistance to abrasion and break resistance, etc. (9). Moreover, the efficiency of these
Polymers in providing optimal cushioning and their capabilities to return energy is still under debate $(7,11)$. In recent years, a great deal of effort has been devoted to the development of nanostructured PUs composites such as Pus nano Clay composites to overcome these disadvantages (9).

Nanoclay particles are a kind of aluminosilicate nanoparticles that can increase tensile strength, tensile modulus, resistance to thermal failure and impact resistance of polymeric composites $(12,13)$. Its makeup is such that can transform polymers into new materials possessing the advantages like lightweight, flexibility, good moldability, high strength, heat stability, and chemical resistance (14). Whit respect to these properties, we hypotheses using Polyurethanes-clay nano-composits in shoe outsole affect the biomechanical variables that related to running such as joint power.

Joint power is a kinetics variable that computes from inverse dynamics by multiplying the joint moment and the joint angular velocity (15-18). It is used to establish the capability of muscle groups to generate or restrain movement (19) and seems to be a valid indicator of a person's ability to control their limbs $(20,21)$ and efficiency of sport activities (22). Knee joint power has been proposed as the primary shock absorber during the stance phase of running (23) and the power generation of knee joint in the second half of stance phase is necessary for pushing the body forward (11). Therefore, knee joint power can be assessed as a related-injury variable. Therefore, this study aimed to investigate the effect of using Polyurethanes-clay nanocomposites in shoe outsole on knee joint power during stance phase of running.

\section{MATERIALS AND METHODS}

The experiments were approved by the Department of Physical Education and Sport Sciences of Mazandaran University. 
Participants. Eighteen healthy men averagely aged 24.15 (SD 3.62 years), weighted 72.26 (SD $6.83 \mathrm{~kg}$ ), with height of 178.0 (SD $4.0 \mathrm{~cm}$ ), with foot size 43 and free of lower extremity injuries and disorders volunteered. They were informed of the procedures and signed an informed consent.

Tools. Data were collected in the Motion Analysis Laboratory of Mazandaran University. Kinetics data were collected with a force plate (Kistler, Winterthur, Switzerland, $60 \mathrm{~cm} * 40 \mathrm{~cm} ; 1000 \mathrm{~Hz})$. Kinematics data were captured using five cameras (JVC-9X00; 200 HZ). These cameras were arranged along an arc on the right side of the force plate that was placed in the middle of $10 \mathrm{~m}$ runway. Video data were collected using the SIMI motion software.

For anatomical trail in order to accomplish three-dimensional calculations of knee joint power eighteen reflective skin markers $(25 \mathrm{~mm})$ were placed on the anatomical landmarks of the right leg. These landmarks consist of: greater trochanter, anterior superior iliac spine, medial and lateral tibial condyles, medial and lateral malleolus, center of calcaneus, fifth metatarsal distal head, second metatarsal distal head, second toe. Also, two rigid thermoplastics with 4 cluster markers firmly secured for tracking three-dimensional movements attached bilaterally to the posterio-lateral aspect of the thigh and shank. Tracking markers were mounted on anterior superior iliac spine, two rigid thermoplastics with 4 cluster markers posterio-lateral aspect of the thigh and shank, center of the heel, lateral aspects and top of the shoe (Fig.1).

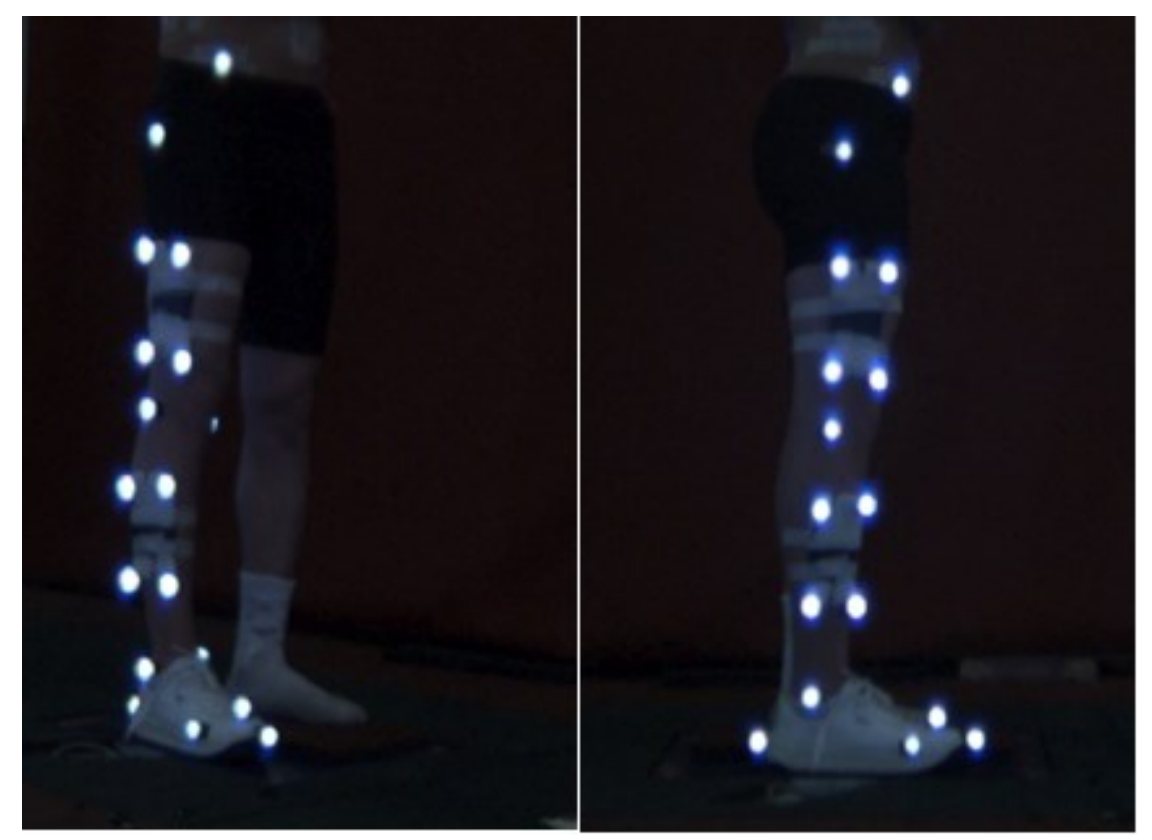

Fig.1. The anatomical marker set

Three pairs of shoes were used in this study. Except their outsole materials, they were totally similar in their weight, size, shape, surface material, quarter panels, vamp and sole design. The materials used in outsoles were Polyurethanes composites (PU), Polyurethanes- clay nano-composites containing $1 \%$ nanoclay particle (NPU1) and Polyurethanes-clay nanocomposites containing $2 \%$ nanoclay particle (NPU2) with hardness of 40, 48 and 56 Shore A, Respectively. A barefoot standing trial was recorded to define the coordinate systems of the 
foot and shank for $5 \mathrm{~s}$ with straight ankle and knee in neutral position and feet aligned parallel to the force platform representing the laboratory coordinate system. Then subjects were tested while running in three shoe conditions at $3.5 \mathrm{~m} . \mathrm{s}^{-}$ ${ }^{1}$ with heel strike pattern. Each runner was given enough time to warm up and become familiar with the specific condition and velocity. Three successful running trials were performed in the shod conditions in a block random order that was defined as which the subject's right foot landed with heel strike pattern on the force plate at speed of about $3.5 \mathrm{~m} . \mathrm{s}^{-1}$ during running. Threedimensional joint movements were calculated according to Cardan sequences (24). The segment inertial parameters were obtained from the adjustments to Zatsiorsky-Seluyanov's parameters as outlined by de Leva (1996) and (25) Newton-Euler inverse dynamics approach was applied to calculate knee joint power. The knee joint power was normalized with respect to the participant's body mass and then timenormalized to 100 data points for each trial, the mean of these trials assumed as final data for each subject. Positive and negative peak values of knee joint power were calculated according to the definition provided by Eng and Winter (1995) in three-dimensional planes (26). Positive power was considered as power generation and negative power was thought as power absorption (16).

Statistical Analysis. All parameters were calculated using a set of programs written in MATLAB $_{2010}$ and Microsoft Excel 2013 from the three-dimensional coordinates previously filtered at $12 \mathrm{~Hz}$ with a low-pass fourth order Butterworth filter (27). One-way repeated measures of ANOVA were used to determine the main effects of different foot-ware on the knee joint power in three- dimensional planes during running by $\mathrm{SPSS}_{20}$ software. The level of significance was set at $\mathrm{p}<0.05$.

\section{RESULTS}

Fig. 2 shows the average curves of knee joint power in three-dimensional planes of motion. In the sagittal plane, almost similar power pattern can be seen in all three shoes in power absorption phase. But in the generation phase, there is a downfall in NPU2 curve that occurred in $30 \%$ to $40 \%$ stance phase and before achieving to the peak of power generation that isn't seen in the power curves of PU and NPU1.

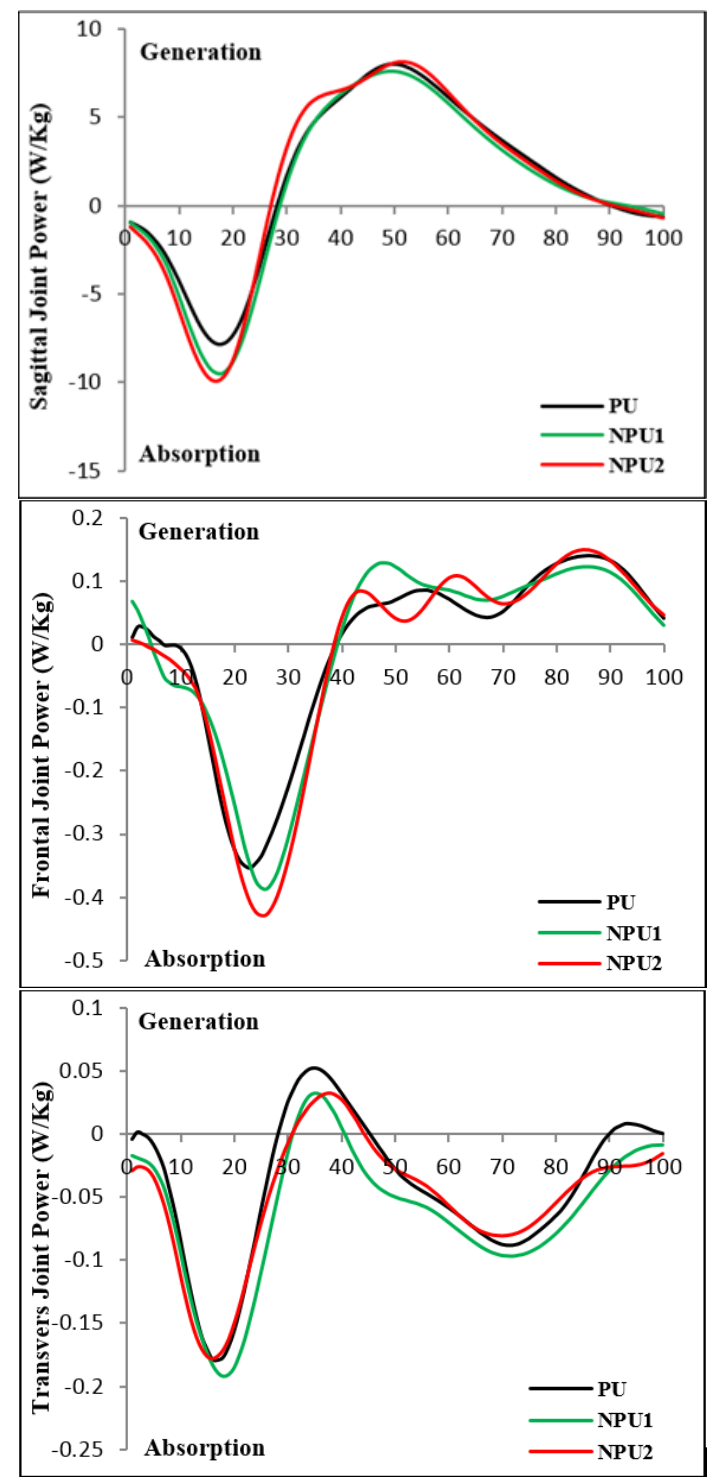

Fig.2. Normalized Knee power curves (W/Kg) for sagittal, frontal and transverse plane during stance phase of PU (black line), NPU1 (green line) and NPU2 (dashed line) running. Positive values correspond to power generation and negative values correspond to power absorption.

In the frontal plane, the patterns of three shoes are totally different in initial $10 \%$ of stance phase. Then, they are almost identical 
until $40 \%$ of stance phase. Again, different patterns can be observed for three shoes in generation phase. The power curve of NPU2 in this plane is more variable than others.

In the transverse plane, the pattern are almost identical in three conditions, while a slight delay can be seen in occurring the peak power generation of NPU2. Also, there is a power generation in late $10 \%$ of stance phase in PU that isn't seen in others, but its magnitude is very small.
There were significant differences between negative peaks of running in PU and NPU2, in the sagittal plane $(\mathrm{P}<0.05)$. Running in NPU2 increased the power absorption of knee joint as compared to PU. However, there were no significant differences between positive peaks in this plane. Also, no significant differences were observed in positive and negative peaks of frontal and transverse plane between three shoe conditions. (Table 1).

Table.1. Mean values (SD) of the peak joint power of knee for sagittal, frontal and transverse planes in PU, NPU1, NPU2 conditions.

\begin{tabular}{c|ccccccc}
\hline $\begin{array}{c}\text { Joint } \\
\text { Power }\end{array}$ & Plane & PU & NPU1 & NPU2 & $\begin{array}{c}\text { P-Value } \\
\text { (PU,NPU1) }\end{array}$ & $\begin{array}{c}\text { P-Value } \\
\text { (PU,NPU2) }\end{array}$ & $\begin{array}{c}\text { P-Value } \\
\text { (NPU1,NPU2) }\end{array}$ \\
\hline \multirow{3}{*}{ Negative } & Sagittal & $8.25(0.65)$ & $10.03(0.85)$ & $10.29(0.95)$ & 0.068 & $\underline{\mathbf{0 . 0 2 5}}$ & 0.824 \\
& Frontal & $0.47(0.09)$ & $0.71(0.19)$ & $0.64(0.17)$ & 0.25 & 0.35 & 0.21 \\
& Transverse & $0.32(0.04)$ & $0.33(0.08)$ & $0.31(0.05)$ & 0.84 & 0.89 & 0.74 \\
\hline \multirow{3}{*}{ Positive } & Sagittal & $9.28(0.65)$ & $8.59(0.82)$ & $9.49(0.83)$ & 0.18 & 0.75 & 0.13 \\
& Frontal & $0.39(0.08)$ & $0.50(0.10)$ & $0.43(0.06)$ & 0.19 & 0.42 & 0.46 \\
& Transverse & $0.13(0.02)$ & $0.11(0.03)$ & $0.12(0.03)$ & 0.46 & 0.81 & 0.65 \\
\hline
\end{tabular}

\section{DISCUSSION AND CONCLUSION}

The aim of this study was to investigate the effect of shoe outsole containing nanoclay particles on knee joint power during stance phase of running. Our results showed that running with NPU2 increased the negative peak of knee joint power as compared to PU. The knee joint is considered as primary power absorbers during the stance phase of running (28) and the quadriceps muscles are responsible for power absorption by eccentric contraction during first stance of running (11). Therefore, greater power absorption by NPU2 indicates better work of these muscles in controlling knee flexion and increasing shock absorbing ability of knee joint. Maybe, it is the result of a greater tensile strength of NPU2 that caused by nanoclay particles.

Our finding showed that the differences between positive peak of knee joint power in the sagittal plane and negative and positive peaks of frontal and transverse plane during stance phase of running weren't significant. These findings are consistence with (6). The lack of statistical significance may be largely because of the limited sample size. One trend was present for the knee joint, which absorbed less energy with the PU as compared to NPU shoes in most part of stance phase of running in three-dimensional planes.

In spite of any significant results in the frontal plane between running with threeshoe conditions, both NPUs shoes increased the knee joint power absorption and generation values as compared to PU in most part of stance phase of running. During most of the stance phase of running the ground reaction force passes form medial side of knee joint $(11,29)$ and power absorption of knee joint in the frontal plane is due to eccentric contraction of knee abductor to restrain adduction moment of ground reaction force. It means that NPUs required greater frontal plane joint powers at knee to control 
external adductor moments during weight acceptance. Moreover, the patterns of three shoes in the second half of stance phase of running in frontal plane are totally different and the pattern of NPU2 has changed, continuously. It has been reported that the increase in power phases of knee joint predispose trauma and injuries to the soft tissues around the knee (30). However, it may be caused by greater stiffness of NPU2.

In the transverse plane, muscles around the knee joint should contract eccentrically in order to control internal rotation of shank in first half of Stance phase of running, and concentrically to rotate shank internally (29, 31). NPUs increased power absorption of knee joint, but PU was better in power generation.

In this study, to control the other factors (e.g. shoe weight, sole shape and geometry) that might affect the results, we produced three shoes exactly with the same properties expected from their materials. It seems that using Polyurethanes-clay nano-composites in shoe outsole can alter the shock absorbing ability in knee joint. With respect to unique mechanical properties of these nanocomposites and to achieve optimal results in all three-dimensional planes, we suggest footwear companies combine these materials and alternation in outsole geometry to improve shock absorbing ability of knee joint and control movements of frontal and transverse planes.

\section{ACKNOWLEDGEMENT}

This project was supported by Faculty of Physical Education \& Sport Science University of Mazandaran - Iran. The NPU shoes used in this study have been recorded at Iran Intellectual Property Office- Patents of the Islamic Republic of Iran.

\section{REFFRENCES}

1. Bischof JE, Abbey AN, Chuckpaiwong B, Nunley JA, Queen RM. Three-dimensional ankle kinematics and kinetics during running in women. Gait \& Posture. 2010;31(4):502-5.

2. Rothschild C. Running Barefoot or in Minimalist Shoes: Evidence or Conjecture? Strength \& Conditioning Journal. 2012;34(2):8-17.

3. Stacoff A, Nigg BM, Reinschmidt C, van den Bogert AJ, Lundberg A. Tibiocalcaneal kinematics of barefoot versus shod running. Journal of Biomechanics. 2000;33(11):1387-95.

4. Ziaei M, Nabavi SH, Mokhtarinia HR, Tabatabai Ghomshe SF. The effect of shoe sole tread groove depth on the gait parameters during walking on dry and slippery surface. The international journal of occupational and environmental medicine. 2013;4(1):27-35.

5. Chambon N, Delattre N, Gueguen N, Berton E, Rao G. Is midsole thickness a key parameter for the running pattern? Gait Posture. 2014;40(1):58-63.

6. Stefanyshyn DJ, Nigg BM. Influence of midsole bending stiffness on joint energy and jump height performance. Medicine and science in sports and exercise. 2000;32(2):471-6.

7. Nigg BM. Biomechanics of Sport Shoes. 1st ed. Alberta, Canada: University of Calgary; 2010. 300 p.

8. Porter DA, \& Schon, L. C. The Shoe in Sports. In Baxter's The Foot and Ankle in Sport. Philadelphia: Mosby Elsevier; 2008.

9. Cao X, James Lee L, Widya T, Macosko C. Polyurethane/clay nanocomposites foams: processing, structure and properties. Polymer. 2005;46(3):775-83.

10. Queen RM, Abbey AN, Wiegerinck JI, Yoder JC, Nunley JA. Effect of shoe type on plantar pressure: A gender comparison. Gait \& Posture. 2010;31(1):18-22.

11. Novacheck TF. The biomechanics of running. Gait Posture. 1998;7(1):77-95.

12. Peter S, Woldesenbet E. Nanoclay syntactic foam composites-High strain rate properties. Materials Science and Engineering: A. 2008;494(1-2):179-87.

13. Zhang G, Shichi T, Takagi K. PET-clay hybrids with improved tensile strength. Materials Letters. 2003;57(12):1858-62.

14. Chang J-H, Kim SJ, Joo YL, Im S. Poly(ethylene terephthalate) nanocomposites by in situ interlayer polymerization: the thermo-mechanical properties and morphology of the hybrid fibers. Polymer. 2004;45(3):91926.

Bassiri, Z., et al. (2014). Ann Appl Sport Sci, 2(3): 33-40. 
15. Neptune RR, Kautz SA, Zajac FE. Contributions of the individual ankle plantar flexors to support, forward progression and swing initiation during walking. J Biomech. 2001;34(11):1387-98.

16. Siegel KL, Kepple TM, Stanhope SJ. Joint moment control of mechanical energy flow during normal gait. Gait Posture. 2004;19(1):69-75.

17. Zajac FE, Neptune RR, Kautz SA. Biomechanics and muscle coordination of human walking. Part I: introduction to concepts, power transfer, dynamics and simulations. Gait Posture. 2002;16(3):215-32.

18. Zajac FE, Neptune RR, Kautz SA. Biomechanics and muscle coordination of human walking: part II: lessons from dynamical simulations and clinical implications. Gait Posture. 2003;17(1):1-17.

19. Bogey RA, Gitter AJ, Barnes LA. Determination of ankle muscle power in normal gait using an EMG-to-force processing approach. J Electromyogr Kinesiol. 2010;20(1):46-54.

20. Olney SJ, Griffin MP, McBride ID. Temporal, kinematic, and kinetic variables related to gait speed in subjects with hemiplegia: a regression approach. Physical therapy. 1994;74(9):872-85.

21. Vardaxis VG, Allard P, Lachance R, Duhaime M. Classification of able-bodied gait using 3-D muscle powers. Human Movement Science. 1998;17(1):121-36.

22. Arampatzis A, Knicker A, Metzler V, Bruggemann GP. Mechanical power in running: a comparison of different approaches. J Biomech. 2000;33(4):457-63.

23. Roberts TJ, Belliveau RA. Sources of mechanical power for uphill running in humans. J Exp Biol. 2005;208(Pt 10):1963-70.

24. Winter DA. Three-Dimensional Kinematics and Kinetics. Biomechanics and Motor Control of Human Movement: John Wiley \& Sons, Inc.; 2009. p. 176-99.

25. de Leva P. Adjustments to Zatsiorsky-Seluyanov's segment inertia parameters. J Biomech. 1996;29(9):1223-30.

26. Eng JJ, Winter DA. Kinetic analysis of the lower limbs during walking: what information can be gained from a three-dimensional model? J Biomech. 1995;28(6):753-8.

27. Nigg BM, Baltich J, Maurer C, Federolf P. Shoe midsole hardness, sex and age effects on lower extremity kinematics during running. J Biomech. 2012;45(9):1692-7.

28. Ounpuu S. The biomechanics of running: a kinematic and kinetic analysis. Instr Course Lect. 1990;39:305-18.

29. Mundermann A, Nigg BM, Humble RN, Stefanyshyn DJ. Foot orthotics affect lower extremity kinematics and kinetics during running. Clinical biomechanics (Bristol, Avon). 2003;18(3):254-62.

30. Shultz SP, Hills AP, Sitler MR, Hillstrom HJ. Body size and walking cadence affect lower extremity joint power in children's gait. Gait Posture. 2010;32(2):248-52.

31. Boyer KA, Andriacchi TP. Changes in running kinematics and kinetics in response to a rockered shoe intervention. Clinical biomechanics (Bristol, Avon). 2009;24(10):872-6.

Bassiri, Z., et al. (2014). Ann Appl Sport Sci, 2(3): 33-40. 
تازههاى علوم كاربردى ورزش

مقاله اصيل

دوره دوم، شماره سوم

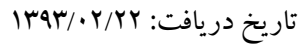

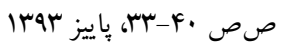

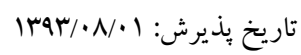

\title{
اثر زيره كفثى حاوى ذرات نانوكلى بر توان مفصل زانو طى مرحله اتكاى دويدن
}

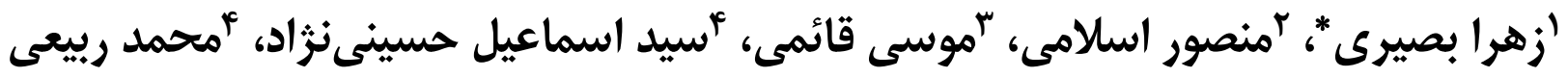

\begin{abstract}
ا. كارشناسى ارشد بيومكانيك ورزشى، دانشكده تربيتبدنى و علوم ورزشى، دانشخاه مازندران، بابلسر، ايران.

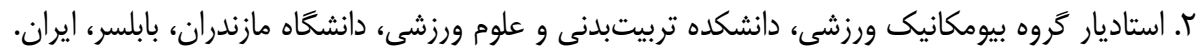

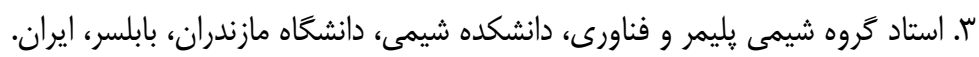

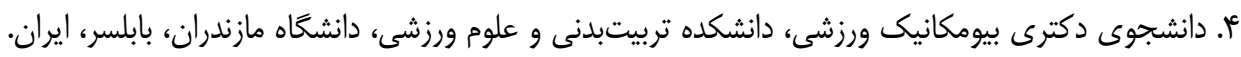

جكيده

افزايش محبوبيت دويدن و آسيبهاى ناشى از آن، گرايش به توسعه ساختار كفش ورزشى را با هدف جلوكيرى از آسيبهاى مختلف دويدن،

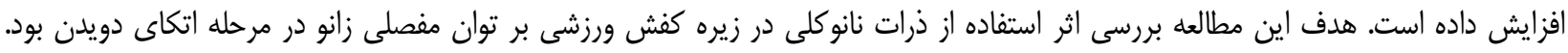

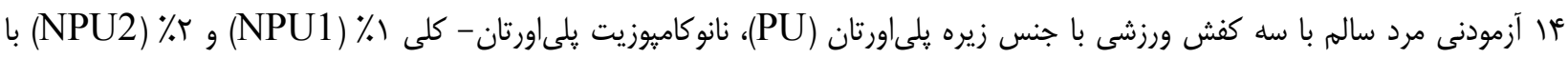

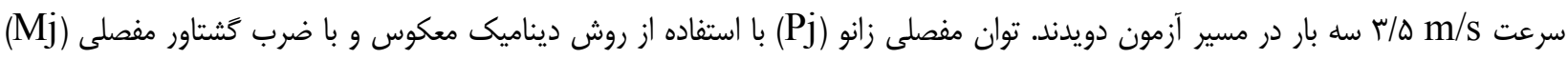

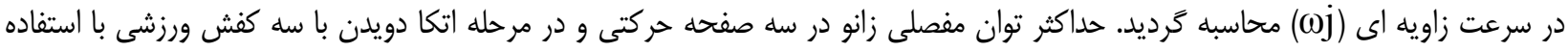

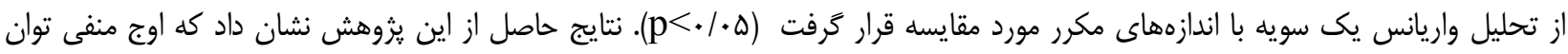

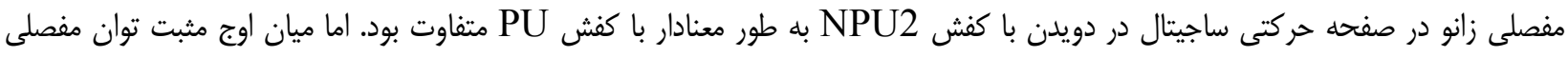

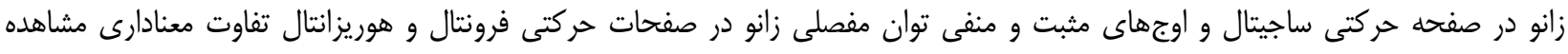

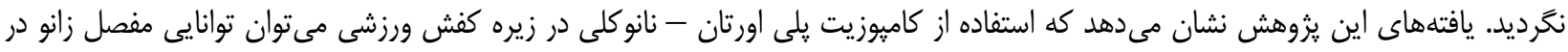
جذب شوك را بهبود بخشد. وازَّان كليدى: زيره كفش، ذرات نانوكلى، توان مفصل زانو، دويدن. 